\title{
As memórias como ponto de partida: os projetos pedagógicos como diagnóstico da realidade institucional dos cursos de Licenciatura em Educação do Campo
}

Heloisa Vitória de Castro Paula ${ }^{1}$, iD Marcelo Cervo Chelotti ${ }^{2}$

${ }^{1}$ Universidade Federal de Catalão - UFCat. Unidade Acadêmica Especial de Educação. Avenida Dr. Lamartine Pinto de Avelar, n. 1120, Setor Universitário. Catalão - GO. Brasil. ${ }^{2}$ Universidade Federal de Santa Maria - UFSM.

Autor para correspondência/Author for correspondence: heloisavcp@hotmail.com

RESUMO. As reflexões sobre a Educação do Campo não podem se apartar do contexto social da luta pela terra. Nesse sentido, a Educação do Campo se constitui para além da prática pedagógica, ao passo que se territorializa em busca de romper as cercas do latifúndio, do capital e da ignorância. Ela emerge dentro do movimento dos trabalhadores rurais sem terra (MST) e transcende os anseios da luta por uma educação para assentados e acampados. Nesta perspectiva, o objetivo deste texto é apresentar a compreensão sobre o processo de institucionalização da Educação do Campo por meio da análise dos Projetos Pedagógicos de Curso dos cursos de Licenciatura em Educação do Campo. Partimos da hipótese de que a Educação do Campo ao se institucionalizar e ampliar sua oferta para além da militância dos movimentos sociais, não mantém a essência em que foi gestada. As análises foram feitas considerando as dimensões: pedagógica, política e geográfica. $\mathrm{O}$ estudo foi delineado por meio da pesquisa teórica e documental. As análises realizadas nos levam a reconhecer a Licenciatura em Educação do Campo como o mais importante território da Educação do Campo, que, por sua vez, apresenta-se como um território em constante disputa.

Palavras-chave: educação do campo, território, licenciatura em educação do campo. 


\title{
Memories as a starting point: pedagogical projects as a diagnosis of institutional reality of courses in an undergraduate Degree in Rural Education
}

\begin{abstract}
Reflections on Rural Education cannot be separated from the social context of the struggle for land. Thus, Rural Education is not just pedagogical practice; it is territorialized in search of breaking barriers of latifundio, capital and ignorance. It emerges within the Landless Workers' Movement (MST in Portuguese) and transcends the aspirations of the education movement for people who live in settlements and camps. In this perspective, this text aims to present the understanding of the institutionalization process of Rural Education by analyzing Pedagogical Course Projects from courses in an Undergraduate Degree in Rural Education. We start from the hypothesis that Field Education, when institutionalized and making it more available beyond the militancy of social movements, does not maintain the essence in which it was created. Analyses were made considering pedagogical, political and geographic dimensions. This research was designed through theoretical and documentary research. The analyses lead us to recognize the Undergraduate degree in Field Education as the most important territory of Rural Education, which, in turn, presents itself as a territory in constant dispute.
\end{abstract}

Keywords: rural education, territory, teacher formation, undergraduate degree in rural education. 


\section{Las memorias como punto de partida: los proyectos pedagógicos como un diagnóstico de la realidad institucional de los cursos de Licencias en la Educación de Campo}

RESUMEN. Las reflexiones sobre la educación rural no pueden apartarse del contexto social de la lucha por la tierra. En este sentido, la Educación del Campo se constituye más allá de la práctica pedagógica, mientras se territorializa en busca de romper las vallas del latifundio, de la capital y de la ignorancia. Surge dentro del Movimiento de Trabajadores Rurales sin Tierra (MST) y trasciende las aspiraciones del movimiento educativo para los colonos y los campistas. En esta perspectiva, el objetivo de este texto es presentar la comprensión sobre el proceso de institucionalización de la Educación Rural a través del análisis de los Proyectos del Curso Pedagógico de la Licenciatura en cursos de Educación Rural. Partimos de la hipótesis de que la Educación del Campo, al institucionalizar y expandir su oferta más allá de la militancia de los movimientos sociales, no mantiene la esencia en la que se creó. Los análisis se realizaron considerando las dimensiones: pedagógica, política y geográfica. La investigación fue diseñada a través de la investigación teórica y documental. Los análisis realizados nos llevan a reconocer el Grado en Educación Rural como el territorio más importante de la Educación Rural, que, a su vez, se presenta como un territorio en constante disputa.

Palabras clave: educación del campo, territorio, formación de profesores, licencias en la educación de campo. 


\section{Introdução}

O estudo sobre a institucionalização da Educação do Campo nos revela que esse processo trouxe novas práticas, novas perspectivas e novas relações com as premissas e a essência da Educação do Campo. A partir desta lógica de criação dos cursos de Licenciatura em Educação do Campo de forma ampliada, refletimos sobre os impactos dessa institucionalização no debate orgânico da Educação do Campo, que não pode se afastar da proposta de uma educação emancipatória, baseada nas lutas sociais.

Para o MST, a formação profissional de educadores se amplia para uma formação de militantes do setor e do Movimento, portanto, essa formação deverá se dar de forma diferenciada, sensibilizando e dialogando sobre as questões do campo, numa esfera social e política. Quando o Movimento trata a formação numa perspectiva dialógica com a realidade do campo, ele quer trazer à tona as questões inerentes ao campo, como as agrárias e de desenvolvimento.

O presente trabalho aborda elementos sobre o processo de institucionalização da Educação do Campo por meio dos cursos de Licenciatura em Educação do Campo. A hipótese que se apresentava era que ao passo que a
Educação do Campo se institucionalizava ela se afastava dos princípios formativos que a constituíram. Para que fosse possível fazer essas reflexões, partimos das memórias do Setor de Educação do MST no que tange aos propósitos apresentados para a Educação do Campo e analisamos os Projetos Pedagógicos de Curso das Licenciaturas em Educação do Campo.

O procedimento metodológico utilizado neste estudo foi a pesquisa documental. As fontes de informações utilizadas foram: os Projetos Pedagógicos de Curso (PPC) dos cursos de Licenciatura em Educação do Campo; os marcos normativos que subsidiam a política de educação específica para o campo; os Editais $n^{0}$ 2/2008, $n^{\circ}$ 9/2009 e $n^{0}$ 02/2012 e os documentos que apresentam o PRONERA e o PROCAMPO como parte das políticas públicas de formação de professores para o campo; e os Boletins e Cadernos Temáticos publicados pelo MST e pelo Iterra desde o ano de 1992.

\section{Diagnóstico e análise documental da institucionalização da Licenciatura em Educação do Campo}

Ao analisarmos os editais do PROCAMPO (2008, 2009, 2012), foi possível perceber que ao mesmo tempo em que se ampliou o número de instituições selecionadas para ofertarem a Licenciatura 
em Educação do Campo, diminuiu-se a exigência de participação orgânica dos movimentos camponeses na construção das propostas. Diante desse processo de institucionalização promovido pelo PROCAMPO e considerando as primeiras iniciativas voltadas para a formação de educadores do campo do MST, inquietamo-nos a compreender se ao passo que a proposta de Educação do Campo se institucionaliza e amplia sua oferta para além da militância dos movimentos sociais, é possível manter a essência em que foi gestada, tendo as matrizes formativas apresentadas pelos movimentos camponeses - "trabalho, a luta social, a organização coletiva, a cultura e a história" - como impulsionadoras desse projeto de educação.

Para compreendermos os princípios da Educação do Campo a partir do MST, foi preciso analisar os Cadernos Temáticos e os Boletins do MST e do Iterra. As memórias presentes nesses documentos foram essenciais para termos um ponto de partida para a análise dos Projetos Pedagógicos de Cursos (PPCs) dos cursos de Licenciatura em Educação do Campo. Ter clareza do que era caro ao Setor de Educação do MST ao propor um projeto de educação para o campo nos traria uma diretriz do que era preciso analisar para identificar a consonância entre o projeto do movimento e o projeto institucional das universidades.

Diante do exposto, as análises dos PPCs dos cursos de Licenciatura em Educação do Campo possibilitaram a reflexão sobre o diálogo entre os cursos oferecidos nas universidades com os preceitos da Educação do Campo apresentados pelos movimentos sociais de luta pela terra.

Desde 2008 foram publicados três editais que visavam:

convocar as Instituições Públicas de
Educação Superior para a a
apresentação de projetos de cursos
regulares de Licenciatura em
Educação do Campo ... para a
formação de professores para a
docência nos anos finais do ensino
fundamental e ensino médio nas
escolas localizadas nas áreas rurais
(Edital, 2008, p. 1).

A convocação de instituições públicas para participarem dos editais para seleção dos projetos se configurou como uma forma de ampliação e continuidade do PROCAMPO. As experiências com a Licenciatura em Educação do Campo se iniciaram em 2007 com os projetos pilotos. Desde o primeiro edital, lançado em 2008, já estava previsto que as instituições de ensino superior pudessem apresentar propostas para cursos regulares, com duração de quatro anos, voltados para a formação de professores para a docência em anos finais do ensino fundamental e 
médio. Portanto, somente no edital de 2012 estava previsto que fossem ofertadas vagas durante três anos consecutivos, sendo essa uma das iniciativas para garantir a continuidade dos cursos dentro das instituições.

Outra especificidade do edital de 2012 que o difere dos dois anteriores e deixa clara a institucionalização dos cursos foi autorizar as IFEs a contratarem de forma efetiva até 15 (quinze) professores e 3 (três) técnicos administrativos para cada curso selecionado. Como incentivo para se iniciar a implantação dos cursos foi paga, em uma única parcela, no primeiro ano, uma ordem de custeio de $\mathrm{R} \$ 4.000,00$ (quatro mil reais) por estudante.

Dentre as condições para participação do edital, estava apresentar um projeto com currículo organizado por áreas de conhecimentos previstas para a docência multidisciplinar: Linguagens e códigos; Ciências Humanas e Sociais; Ciências da Natureza e Matemática; e
Ciências Agrárias. Nos editais de 2008 e 2009 era recomendado que preferencialmente as propostas contemplassem a área de Ciências da Natureza, com a justificativa de se reverter a escassez de docentes habilitados nessa área nas escolas no campo; no edital de 2012 essa prerrogativa não está exposta.

As instituições deveriam apresentar projetos específicos em Educação do Campo, com propostas capazes de valorizá-la e temas relevantes aos povos do campo. Mediante a identificação das instituições selecionadas para ofertarem a Licenciatura em Educação do Campo, elaboramos os quadros a partir de consultas ao portal oficial do Ministério da Educação (MEC), a sites de busca e aos portais das universidades.

Os editais de 2008 e 2009 selecionaram 23 instituições, dentre elas, as instituições piloto, como pode ser visto no Quadro 1:

Quadro 1 - Instituições públicas selecionadas nos editais de 2008 e 2009 do PROCAMPO para oferta do curso de Licenciatura em Educação do Campo.

\begin{tabular}{|c|c|c|c|c|c|}
\hline $\mathbf{N}$. & UF & Instituição & Edital & $\begin{array}{c}\text { Área de } \\
\text { Conhecimento }\end{array}$ & Status \\
\hline & & \multicolumn{3}{|c|}{ REGIÃO NORTE } & \\
\hline 01 & AP & $\begin{array}{lrr}\text { Universidade } \quad \text { Federal } & \text { do } \\
\text { Amapá/Campus Mazagão } & \end{array}$ & $2008 / 2009 / 2012$ & $\begin{array}{l}\text { Ciências agrárias e } \\
\text { natureza, com ênfase } \\
\text { em Agronomia e } \\
\text { Biologia }\end{array}$ & Ativo \\
\hline 02 & PA & $\begin{array}{lll}\text { Universidade } & \text { Federal } & \text { do } \\
\text { Pará/Altamira } & & \end{array}$ & $2009 / 2012$ & $\begin{array}{l}\text { Linguagens e } \\
\text { códigos; Ciências da } \\
\text { Natureza }\end{array}$ & Ativo \\
\hline 03 & $\mathbf{P A}$ & $\begin{array}{ll}\text { Federal do } \\
\end{array}$ & $2009 / 2012$ & Ciências agrária e da & Ativo \\
\hline
\end{tabular}




\begin{tabular}{|c|c|c|c|c|c|}
\hline & & Pará/Cametá & & Natureza & \\
\hline 04 & PA & $\begin{array}{l}\text { IFPA (Altamira, Bragança, } \\
\text { Breves, Gurupá, Moju e Marabá) }\end{array}$ & $\begin{array}{l}\text { EDITAL } 2009 \\
\text { PARFOR } 2011\end{array}$ & $\begin{array}{l}\text { Ciências Humanas e } \\
\text { Sociais }\end{array}$ & Ativo \\
\hline & \multicolumn{5}{|c|}{ REGIÃO CENTRO OESTE } \\
\hline 05 & DF & $\begin{array}{ll}\text { Universidade } & \text { de } \\
\text { Brasília/Planaltina } & \end{array}$ & $\begin{array}{l}\text { 2008/2009/2012 } \\
\text { Piloto }\end{array}$ & $\begin{array}{l}\text { Arte, Literatura e } \\
\text { Linguagem/Ciências } \\
\text { da } \\
\text { Natureza/Matemática }\end{array}$ & Ativo \\
\hline \multicolumn{6}{|c|}{ REGIÃO SUDESTE } \\
\hline 06 & MG & Universidade Federal de MG & $\begin{array}{c}2004 / 2008 / 2009 \\
\text { Piloto }\end{array}$ & $\begin{array}{l}\text { Matemática; } \\
\text { da Viências } \\
\text { Natureza, Ciências } \\
\text { Sociais }\end{array}$ & Ativo \\
\hline 07 & MG & $\begin{array}{l}\text { Universidade Estadual de Montes } \\
\text { Claros }\end{array}$ & 2008 & $\begin{array}{lr}\text { PEDAGOGIA- } \\
\text { EDUCAÇÃO DO } \\
\text { CAMPO. Não } \\
\begin{array}{ll}\text { localizada a área } \\
\text { multidisciplinar }\end{array}\end{array}$ & $\begin{array}{c}\text { Encerrou } \\
\text { Turma única }\end{array}$ \\
\hline 08 & $\mathbf{R J}$ & $\begin{array}{l}\text { Fundação de Apoio à Escola } \\
\text { Técnica do Estado do Rio de } \\
\text { Janeiro/ } \\
\text { Instituto Superior de Educação } \\
\text { Professor Aldo Muylaert }\end{array}$ & 2008 & $\begin{array}{l}\text { Ciências da Natureza } \\
\text { (Física, Química e } \\
\text { Biologia) } r \\
\text { Matemática, com } \\
\text { ênfase em Ciências } \\
\text { Agrárias. }\end{array}$ & Não iniciou \\
\hline \multicolumn{6}{|c|}{ REGIÃO NORDESTE } \\
\hline 09 & BA & Universidade Federal da Bahia & $\begin{array}{l}2008 \\
\text { Piloto }\end{array}$ & $\begin{array}{l}\text { Linguagens } r \text { e } \\
\text { Códigos, Ciências } \\
\text { Humanas e Sociais e } \\
\text { Ciências Exatas e da } \\
\text { Natureza }\end{array}$ & Ativo \\
\hline 10 & MA & $\begin{array}{lll}\text { Universidade } & \text { Federal } & \text { do } \\
\text { Maranhão } & & \end{array}$ & $2008 / 2009 / 2012$ & $\begin{array}{l}\text { Ciências Agrárias; } \\
\text { Ciências da Natureza } \\
\text { e Matemática }\end{array}$ & Ativo \\
\hline 11 & MA & $\begin{array}{l}\text { Instituto } \text { Federal de } \text { Educação, } \\
\text { Ciência e Tecnologia do } \\
\text { Maranhão/Campus } \\
\text { Luis/Maracanã }\end{array}$ & $2009 / 2012$ & $\begin{array}{l}\text { Ciências Agrárias; } \\
\text { Ciências da Natureza } \\
\text { e Matemática }\end{array}$ & Ativo \\
\hline 12 & $\overline{\mathbf{P E}}$ & $\begin{array}{l}\text { Autarquia Educacional de Ensino } \\
\text { superior de Arco Verde }\end{array}$ & 2008 & Não localizada & $\begin{array}{l}\text { Encerrou } \\
\text { Turma única }\end{array}$ \\
\hline 13 & $\mathbf{P E}$ & $\begin{array}{l}\text { Autarquia } \\
\text { Talhadacacional }\end{array}$ & 2008 & Não localizada & $\begin{array}{c}\text { Encerrou } \\
\text { Turma única }\end{array}$ \\
\hline 14 & PE & $\begin{array}{l}\text { Autarquia Educacional Belemita - } \\
\text { Centro de Ensino Superior do } \\
\text { Vale do São Francisco }\end{array}$ & 2009 & $\begin{array}{lr}\text { Habilitação } & \text { em } \\
\text { Linguagens } & \text { e } \\
\text { Códigos } & \text { e } \\
\text { Habilitação } & \text { em } \\
\text { Ciências da Natureza } \\
\text { e Matemática }\end{array}$ & $\begin{array}{c}\text { Encerrou } \\
\text { Turma única }\end{array}$ \\
\hline
\end{tabular}




\begin{tabular}{|c|c|c|c|c|c|}
\hline 15 & $\mathbf{P E}$ & Universidade de Pernambuco & 2008 & Não consta & $\begin{array}{c}\text { Encerrou } \\
\text { Turma única }\end{array}$ \\
\hline 16 & PE & $\begin{array}{lll}\text { Autarquia } & \text { Educacional de } \\
\text { Salgueiro } & & \end{array}$ & 2008 & Não consta & $\begin{array}{l}\text { Turma única } \\
\text { Não iniciou }\end{array}$ \\
\hline 17 & $\mathbf{P E}$ & $\begin{array}{l}\text { Autarquia Educacional de } \\
\text { Afogados da Ingazeira }\end{array}$ & 2008 & Não consta & Não iniciou \\
\hline 18 & $\mathbf{P E}$ & Autarquia Educacional do Araripe & 2008 & Não consta & Não iniciou \\
\hline 19 & $\mathbf{P E}$ & $\begin{array}{l}\text { Autarquia Educacional de Ensino } \\
\text { superior de Arco Verde }\end{array}$ & 2008 & Não consta & $\begin{array}{c}\text { Encerrou } \\
\text { Turma única }\end{array}$ \\
\hline 20 & SE & Universidade Federal de Sergipe & $\begin{array}{l}2008 \\
\text { Piloto }\end{array}$ & $\begin{array}{l}\text { Linguagens } \\
\text { Códigos, Ciências } \\
\text { Humanas e Sociais e } \\
\text { Ciências Exatas e da } \\
\text { Natureza }\end{array}$ & Encerrada \\
\hline \multicolumn{6}{|c|}{ REGIÃO SUL } \\
\hline 21 & PR & $\begin{array}{l}\text { Universidade Estadual do Oeste } \\
\text { do Paraná }\end{array}$ & 2008 & $\begin{array}{l}\text { Ciências da Natureza } \\
\text { e Matemática ou } \\
\text { Ciências Agrárias }\end{array}$ & $\begin{array}{c}\text { Encerrou } \\
\text { Turma única }\end{array}$ \\
\hline 22 & PR & $\begin{array}{l}\text { Universidade Estadual do Centro } \\
\text { Oeste do Paraná }\end{array}$ & 2008 & $\begin{array}{l}\text { Ciências da Natureza } \\
\text { e Matemática ou } \\
\text { Linguagens }\end{array}$ & $\begin{array}{l}\text { Encerrou } \\
\text { Turma única }\end{array}$ \\
\hline 23 & SC & $\begin{array}{l}\text { Universidade Federal de Santa } \\
\text { Catarina/Florianópolis }\end{array}$ & 2008/2009/2012 & $\begin{array}{l}\text { Ciências da Natureza; } \\
\text { Matemática; Ciências } \\
\text { Agrárias }\end{array}$ & Ativo \\
\hline
\end{tabular}

Fonte: Paula (2020).

As universidades selecionadas no edital de 2008 não constam no site do MEC/PROCAMPO. Através de pesquisas em sites de busca, foi localizada uma reportagem "Educação do Campo recebe 24 projetos", publicada no Portal do MEC em 11 de agosto de 2008. Dentro da reportagem há um link que dá acesso a uma lista de "Instituições que aderiram ao PROCAMPO e iniciaram o curso". A partir daí, tomamos conhecimento de dez cursos ofertados por meio de Autarquias no estado de Pernambuco e que não apareciam nos levantamentos que havíamos feito anteriormente. Em contato com a Coordenação Geral de Educação do Campo não nos foi disponibilizada uma lista que confirmasse o conhecimento sobre esses cursos.

Por meio de pesquisas realizadas na internet foi possível localizar documentos e artigos acadêmicos que falam da existência desses cursos nessas instituições, podendo dar indícios de que os mesmos foram ofertados, portanto, com o compromisso de formar somente uma turma. A partir daí, fizemos contatos telefônicos com a administradora das 
Autarquias e confirmamos a existência da oferta de turma única do curso, subsidiada pelo Fundo Nacional de Desenvolvimento da Educação (FNDE).

A identificação dos cursos que foram selecionados no edital de 2012 pôde ser encontrada no portal oficial do MEC. No edital de 2012 foram escolhidos 45 projetos. O Quadro 2 apresenta as instituições selecionadas, os editais que já haviam sido contemplados e o andamento dos cursos:

Quadro 2 - Instituições públicas selecionadas no edital 2012/PROCAMPO para ofertaram o curso de Licenciatura em Educação do Campo.

\begin{tabular}{|c|c|c|c|c|c|}
\hline $\mathbf{N}$. & UF & Instituição & Edital & Área de Conhecimento & Status \\
\hline \multicolumn{6}{|c|}{ REGIÃO NORTE } \\
\hline 01 & AP & $\begin{array}{l}\text { Universidade Federal do } \\
\text { Amapá/Campus Mazagão }\end{array}$ & 2008/2009/2012 & $\begin{array}{l}\text { Ciências agrárias e } \\
\text { natureza, com ênfase em } \\
\text { Agronomia e Biologia }\end{array}$ & Ativo \\
\hline 02 & $\mathbf{P A}$ & $\begin{array}{l}\text { Universidade Federal do } \\
\text { Pará/ Campus Abaetetuba }\end{array}$ & 2012 & $\begin{array}{l}\text { Ciências Naturais; } \\
\text { Matemática e } \\
\text { Linguagem: códigos e } \\
\text { suas tecnologias }\end{array}$ & Ativo \\
\hline 03 & PA & $\begin{array}{c}\text { Universidade Federal do } \\
\text { Pará/Altamira }\end{array}$ & $2009 / 2012$ & $\begin{array}{l}\text { Linguagens e códigos; } \\
\text { Ciências da Natureza }\end{array}$ & Ativo \\
\hline 04 & $\mathbf{P A}$ & $\begin{array}{c}\text { Universidade Federal do } \\
\text { Pará/Cametá }\end{array}$ & $2009 / 2012$ & $\begin{array}{c}\text { Ciências agrária e da } \\
\text { Natureza }\end{array}$ & Ativo \\
\hline 05 & PA & $\begin{array}{c}\text { Universidade Federal do } \\
\text { Pará/Marabá }\end{array}$ & 2012 & $\begin{array}{c}\text { Habilitação em Ciências } \\
\text { Humanas e Sociais; } \\
\text { Habilitação em } \\
\text { Linguagem, Letras e } \\
\text { Artes; Habilitação em } \\
\text { Ciências Agrárias e da } \\
\text { Natureza; Habilitação em } \\
\text { Matemática e Sistemas de } \\
\text { Informação }\end{array}$ & Ativo \\
\hline 06 & PA & $\begin{array}{l}\text { Universidade Federal do } \\
\text { Sul e Sudeste do Pará } \\
\text { (UNIFESSPA)/Marabá }\end{array}$ & 2012 & $\begin{array}{l}\text { Linguagens e Letras ou } \\
\text { Ciências Humanas e } \\
\text { Sociais ou Ciências } \\
\text { Agrárias e da Natureza } \\
\text { ou Matemática } \\
\end{array}$ & Ativo \\
\hline 07 & RO & $\begin{array}{c}\text { Universidade Federal de } \\
\text { Rondônia/Campus Rolim } \\
\text { de Moura }\end{array}$ & 2012 & $\begin{array}{l}\text { Ciências da Natureza; } \\
\text { Ciências Humanas }\end{array}$ & Ativo \\
\hline 08 & $\mathbf{R R}$ & $\begin{array}{c}\text { Universidade Federal de } \\
\text { Roraima/Campus } \\
\text { Paricarana }\end{array}$ & 2012 & $\begin{array}{c}\text { Ciências Humanas e } \\
\text { Sociais; Ciências da } \\
\text { Natureza e Matemática }\end{array}$ & Ativo \\
\hline 09 & TO & $\begin{array}{l}\text { Universidade Federal do } \\
\text { Tocantins/Campus Arraias }\end{array}$ & 2012 & $\begin{array}{l}\text { Linguagens e códigos } \\
\text { (habilitação em artes } \\
\text { visuais e música) }\end{array}$ & Ativo \\
\hline 10 & TO & $\begin{array}{l}\text { Universidade Federal do } \\
\text { Tocantins/Campus }\end{array}$ & 2012 & $\begin{array}{l}\text { Linguagens e códigos } \\
\text { (habilitação em artes }\end{array}$ & Ativo \\
\hline
\end{tabular}




\begin{tabular}{|c|c|c|c|c|c|}
\hline & & Tocantinópolis & & visuais e música) & \\
\hline & \multicolumn{5}{|c|}{ REGIÃO CENTRO OESTE } \\
\hline 11 & DF & $\begin{array}{l}\text { Universidade de } \\
\text { Brasília/Planaltina }\end{array}$ & $\begin{array}{l}\text { 2008/2009/2012 } \\
\text { Piloto }\end{array}$ & $\begin{array}{c}\text { Arte, Literatura e } \\
\text { Linguagem/Ciências da } \\
\text { Natureza/Matemática }\end{array}$ & Ativo \\
\hline 12 & GO & $\begin{array}{l}\text { Universidade Federal de } \\
\text { Goiás/Regional Catalão }\end{array}$ & 2012 & Ciências da Natureza & Ativo \\
\hline 13 & GO & $\begin{array}{c}\text { Universidade Federal de } \\
\text { Goiás/Regional Cidade de } \\
\text { Goiás }\end{array}$ & 2012 & Ciências da Natureza & Ativo \\
\hline 14 & MS & $\begin{array}{c}\text { Universidade Federal da } \\
\text { Grande Dourados }\end{array}$ & 2012 & $\begin{array}{c}\text { Ciências da Natureza e } \\
\text { Ciências Humanas }\end{array}$ & Ativo \\
\hline 15 & MS & $\begin{array}{l}\text { Universidade Federal do } \\
\text { Mato Grosso do Sul }\end{array}$ & 2012 & $\begin{array}{l}\text { Ciências Humanas e } \\
\text { sociais; Linguagens e } \\
\text { Códigos; Matemática }\end{array}$ & Ativo \\
\hline 16 & MT & $\begin{array}{c}\text { IF Educação Ciência } \\
\text { Tecnologia MT }\end{array}$ & 2012 & Não consta & Não iniciou \\
\hline \multicolumn{6}{|c|}{ REGIÃO SUDESTE } \\
\hline 17 & ES & $\begin{array}{c}\text { Universidade Federal do } \\
\text { Espírito Santo/Campus } \\
\text { Goiabeiras } \\
\end{array}$ & 2012 & $\begin{array}{c}\text { Ciências Humanas e } \\
\text { sociais; Linguagens e } \\
\text { Códigos }\end{array}$ & Ativo \\
\hline 18 & ES & $\begin{array}{c}\text { Universidade Federal do } \\
\text { Espírito Santo/ Campus } \\
\text { São Mateus }\end{array}$ & 2012 & $\begin{array}{c}\text { Linguagens e } \\
\text { códigos;Ciências } \\
\text { Humanas e Sociais; } \\
\text { Ciências da } \\
\text { Natureza;Matemática e } \\
\text { Ciências Agrárias }\end{array}$ & Ativo \\
\hline 19 & MG & $\begin{array}{l}\text { Universidade Federal de } \\
\text { Viçosa }\end{array}$ & 2012 & Ciências da Natureza & Ativo \\
\hline 20 & MG & $\begin{array}{c}\text { Universidade Federal do } \\
\text { Triângulo Mineiro }\end{array}$ & 2012 & $\begin{array}{c}\text { Ciências da Natureza; } \\
\text { Matemática }\end{array}$ & Ativo \\
\hline 21 & MG & $\begin{array}{c}\text { Universidade Federal dos } \\
\text { Vales do Jequitinhonha e } \\
\text { Mucuri/Diamantina } \\
\end{array}$ & 2012 & $\begin{array}{l}\text { Linguagens e códigos; } \\
\text { Ciências da Natureza }\end{array}$ & Ativo \\
\hline 22 & $\mathbf{R J}$ & $\begin{array}{c}\text { Universidade Federal } \\
\text { Fluminense/Campus Sto } \\
\text { Antonio de Pádua }\end{array}$ & 2012 & $\begin{array}{c}\text { Ciências Humanas e } \\
\text { sociais }\end{array}$ & Ativo \\
\hline 23 & $\mathbf{R J}$ & $\begin{array}{l}\text { Universidade Federal } \\
\text { Rural do Rio de } \\
\text { Janeiro/Seropédica }\end{array}$ & 2012 & $\begin{array}{l}\text { Ciências Sociais e } \\
\text { Humanidades }\end{array}$ & Ativo \\
\hline \multicolumn{6}{|c|}{ REGIÃO NORDESTE } \\
\hline 24 & BA & $\begin{array}{c}\text { Universidade Federal do } \\
\text { Recôncavo Baiano/Campus } \\
\text { Amargosa }\end{array}$ & 2012 & Ciências Agrárias & Ativo \\
\hline 25 & BA & $\begin{array}{c}\text { Universidade Federal do } \\
\text { Recôncavo Baiano/Feira de } \\
\text { Santana }\end{array}$ & 2012 & $\begin{array}{c}\text { Ciências da Natureza e } \\
\text { Matemática }\end{array}$ & Ativo \\
\hline 26 & $\mathbf{B A}$ & $\begin{array}{c}\text { Universidade Estadual da } \\
\text { Bahia/Itaberaba }\end{array}$ & $\begin{array}{l}\text { Edital 2010/ } \\
\text { Início } 2012\end{array}$ & & Não iniciou \\
\hline 27 & MA & $\begin{array}{c}\text { Universidade Federal do } \\
\text { Maranhão }\end{array}$ & $2008 / 2009 / 2012$ & $\begin{array}{c}\text { Ciências Agrárias; } \\
\text { Ciências da Natureza e }\end{array}$ & Ativo \\
\hline
\end{tabular}




\begin{tabular}{|c|c|c|c|c|c|}
\hline & & & & Matemática & \\
\hline 28 & MA & $\begin{array}{c}\text { Instituto Federal de } \\
\text { Educação, Ciência e } \\
\text { Tecnologia do } \\
\text { Maranhão/Campus São } \\
\text { Luis/Maracanã }\end{array}$ & $2009 / 2012$ & $\begin{array}{c}\text { Ciências Agrárias; } \\
\text { Ciências da Natureza e } \\
\text { Matemática }\end{array}$ & Ativo \\
\hline 29 & PB & $\begin{array}{c}\text { Universidade Federal da } \\
\text { Paraíba }\end{array}$ & 2012 & Não consta & Não iniciou \\
\hline 30 & PI & $\begin{array}{c}\text { Universidade Federal do } \\
\text { Piauí/Campus Cinobelina } \\
\text { Elvas Bom Jesus }\end{array}$ & 2012 & $\begin{array}{c}\text { Ciências Humanas e } \\
\text { Sociais }\end{array}$ & Ativo \\
\hline 31 & PI & $\begin{array}{l}\text { Universidade Federal do } \\
\text { Piauí/Campus Floriano }\end{array}$ & 2012 & Ciências da Natureza & Ativo \\
\hline 32 & PI & $\begin{array}{c}\text { Universidade Federal do } \\
\text { Piauí/Campus Picos }\end{array}$ & 2012 & Ciências da Natureza & Ativo \\
\hline 33 & PI & $\begin{array}{l}\text { Universidade Federal do } \\
\text { Piauí/Campus Teresina }\end{array}$ & 2012 & Ciências da Natureza & Ativo \\
\hline 34 & $\mathbf{R N}$ & $\begin{array}{l}\text { Universidade Federal Rural } \\
\text { do Semi árido/UFERSA }\end{array}$ & 2012 & $\begin{array}{c}\text { Ciências da Natureza; } \\
\text { Ciências Humanas e } \\
\text { Sociais }\end{array}$ & Ativo \\
\hline \multicolumn{6}{|c|}{ REGIÃO SUL } \\
\hline 35 & PR & $\begin{array}{l}\text { Universidade Federal do } \\
\text { Paraná/ Litoral Sul }\end{array}$ & 2012 & Ciências da Natureza & Ativo \\
\hline 36 & PR & $\begin{array}{c}\text { Universidade Tecnológica } \\
\text { Federal do Paraná/ Campus } \\
\text { Dois Vizinhos } \\
\end{array}$ & 2012 & $\begin{array}{c}\text { Ciências da Natureza; } \\
\text { Ciências Agrárias; } \\
\text { Matemática } \\
\end{array}$ & Ativo \\
\hline 37 & PR & $\begin{array}{c}\text { Universidade Federal da } \\
\text { Fronteira Sul/Laranjeiras } \\
\text { do Sul }\end{array}$ & $\begin{array}{l}2010 \text { (sem edital) } \\
2012\end{array}$ & $\begin{array}{c}\text { Ciências Naturais e } \\
\text { Matemática e Ciências } \\
\text { Agrárias; Ciências } \\
\text { Humanas e sociais }\end{array}$ & Ativo \\
\hline 38 & RS & $\begin{array}{l}\text { Universidade Federal da } \\
\text { Fronteira Sul/Erechim }\end{array}$ & 2012 & Ciências da Natureza & Ativo \\
\hline 39 & RS & $\begin{array}{c}\text { Universidade Federal do } \\
\text { Rio Grande do Sul/Porto } \\
\text { Alegre }\end{array}$ & 2012 & Ciências da Natureza & Ativo \\
\hline 40 & RS & $\begin{array}{l}\text { Universidade Federal do } \\
\text { Rio Grande do Sul/Litoral } \\
\text { Norte }\end{array}$ & 2012 & Ciências da Natureza & Ativo \\
\hline 41 & RS & $\begin{array}{l}\text { Universidade Federal do } \\
\text { Rio Grande/ }\end{array}$ & 2012 & $\begin{array}{l}\text { Ciências da Natureza e } \\
\text { Ciências Agrárias }\end{array}$ & Ativo \\
\hline 42 & RS & $\begin{array}{l}\text { Universidade Federal do } \\
\text { Pampa/ Dom Pedrito }\end{array}$ & 2012 & Ciências da Natureza & Ativo \\
\hline 43 & RS & $\begin{array}{c}\text { Instituto Federal } \\
\text { Farroupilha/Jaguari }\end{array}$ & 2012 & $\begin{array}{c}\text { Ciências da Natureza e } \\
\text { Ciências Agrárias }\end{array}$ & Ativo \\
\hline 44 & SC & $\begin{array}{l}\text { Universidade Federal de } \\
\text { Santa } \\
\text { Catarina/Florianópolis }\end{array}$ & 2008/2009/2012 & $\begin{array}{c}\text { Ciências da Natureza; } \\
\text { Matemática; Ciências } \\
\text { Agrárias }\end{array}$ & Ativo \\
\hline 45 & SC & $\begin{array}{c}\text { Instituto Federal de Santa } \\
\text { Catarina/Canoinhas }\end{array}$ & 2012 & Não consta & Não iniciou \\
\hline
\end{tabular}

Fonte: Paula (2020). 
O resultado da seleção do edital de 2012 possibilitou identificar as instituições que deram continuidade aos seus projetos e aquelas que propuseram novos projetos. Durante as pesquisas surpreendentemente nos deparamos com instituições que ofertavam o curso de Licenciatura em Educação do Campo, mas não haviam sido selecionadas por meio de editais que previam que os cursos estivessem fundamentados nas especificidades apresentadas pela Resolução FNDE n.
20/2012 no que tange ao ponto de vista político-pedagógico, operacional e logístico.

A identificação desses cursos nos levou a apontar uma possível substituição de propostas que foram selecionadas, mas não foram iniciadas, ou mesmo iniciativas independentes do PROCAMPO. Os cursos que ofertam a Licenciatura em Educação do Campo e que não concorreram aos editais estão apresentados no Quadro 3:

Quadro 3 - instituições públicas que ofertaram o curso de Licenciatura em Educação do Campo sem terem sido contempladas nos editais do PROCAMPO.

\begin{tabular}{|c|c|c|c|c|c|}
\hline $\mathbf{N}$. & UF & Instituição & Edital & Área de Conhecimento & Status \\
\hline 01 & SP & $\begin{array}{c}\text { Universidade Estadual de } \\
\text { Taubaté }\end{array}$ & $\begin{array}{c}2011 \\
\text { FNDE/SECADI } \\
\text { Programa }\end{array}$ & $\begin{array}{c}\text { Ciências da Natureza e } \\
\text { Matemática }\end{array}$ & $\begin{array}{c}\text { Encerrou } \\
\text { Turma única }\end{array}$ \\
\hline 02 & AL & $\begin{array}{l}\text { Universidade Estadual de } \\
\text { Alagoas }\end{array}$ & $\begin{array}{c}2011 \\
\text { FNDE/SECADI }\end{array}$ & $\begin{array}{c}\text { Linguagens, arte e } \\
\text { literatura; Ciências da } \\
\text { vida e da natureza e } \\
\text { Matemática }\end{array}$ & $\begin{array}{c}\text { Encerrou } \\
\text { Turma única }\end{array}$ \\
\hline 03 & $\mathrm{CE}$ & $\begin{array}{l}\text { Universidade Regional do } \\
\text { Cariri (URCA)/Crato }\end{array}$ & $\begin{array}{c}2011 \\
\text { FNDE/SECADI }\end{array}$ & $\begin{array}{c}\text { Ciências da Natureza e } \\
\text { Matemática }\end{array}$ & Ativo \\
\hline 04 & $\mathbf{C E}$ & $\begin{array}{l}\text { Universidade Estadual do } \\
\text { Ceará/Limoeiro do Norte }\end{array}$ & $\begin{array}{c}2011 \\
\text { FNDE/SECADI } \\
\text { Programa }\end{array}$ & $\begin{array}{l}\text { Ciências da Natureza e } \\
\text { Linguagem e códigos }\end{array}$ & $\begin{array}{c}\text { Encerrou } \\
\text { Turma única }\end{array}$ \\
\hline 05 & PB & $\begin{array}{c}\text { Universidade Federal de } \\
\text { Campina Grande/Campus } \\
\text { Sumé }\end{array}$ & $\begin{array}{c}\text { Não foi } \\
\text { contemplada em } \\
\text { edital. }\end{array}$ & $\begin{array}{l}\text { Linguagens e Códigos, } \\
\text { Ciências Humanas e } \\
\text { Sociais e Ciências } \\
\text { Exatas e da Natureza }\end{array}$ & Ativo \\
\hline 06 & $\mathbf{R N}$ & $\begin{array}{c}\text { Instituto Federal de } \\
\text { Educação, Ciência e } \\
\text { Tecnologia do RN/Campus } \\
\text { Canguaretama }\end{array}$ & $\begin{array}{c}2016 \\
\text { Sem edital }\end{array}$ & $\begin{array}{c}\text { Ciências Humanas e } \\
\text { Sociais ou Matemática }\end{array}$ & Ativo \\
\hline 07 & PR & $\begin{array}{c}\text { Universidade Federal da } \\
\text { Fronteira Sul/Laranjeiras do } \\
\text { Sul }\end{array}$ & $\begin{array}{c}2010 \text { (sem edital) } \\
2012\end{array}$ & $\begin{array}{c}\text { Ciências Naturais e } \\
\text { Matemática e Ciências } \\
\text { Agrárias; Ciências } \\
\text { Humanas e sociais }\end{array}$ & Ativo \\
\hline 08 & RS & $\begin{array}{c}\text { Universidade Federal de } \\
\text { Santa Maria }\end{array}$ & Sem edital & Educação do Campo & $\begin{array}{l}\text { ATIVO } \\
\text { EAD }\end{array}$ \\
\hline 09 & RS & $\begin{array}{l}\text { Universidade Federal de } \\
\text { Pelotas }\end{array}$ & Sem edital & Educação do Campo & $\begin{array}{l}\text { ATIVO } \\
\text { EAD }\end{array}$ \\
\hline
\end{tabular}

Fonte: Paula (2020). 
Após realizarmos o levantamento das instituições que já ofertaram ou foram selecionadas para ofertarem o curso de Licenciatura em Educação do Campo, procedemos à busca pelos Projetos Políticos Pedagógicos dos cursos para que pudéssemos fazer as análises a que nos propusemos. Iniciamos o envio de e-mails para os contatos informados pela Coordenação Geral de Educação do Campo. Foi enviado e-mail aos coordenadores dos cursos em andamento. A solicitação foi enviada para 40 (quarenta) coordenadores em exercício que faziam parte da lista disponibilizada pela Coordenação Geral de Educação do Campo. Desse número, tivemos o retorno de 10 (dez) coordenadores. Muitos e-mails retornaram por não existirem os endereços. Diante desse impedimento, realizamos consultas nas páginas oficiais dos cursos, atualizamos os contatos e reenviamos os $e$ mails, porém, continuamos sem retorno.

Mediante a ausência considerável de retornos, demos início a consultas às páginas oficiais das instituições e a sites de busca na internet para termos acesso aos PPCs, partindo do entendimento de que esses são documentos públicos, aos quais poderíamos ter acesso através de consulta simples nas páginas oficiais. Após essa busca, tivemos acesso a 38 (trinta e oito) documentos. Desses procedimentos, conseguimos ter acesso a 48 (quarenta e oito) documentos dos 76 (setenta e seis) cursos identificados.

A partir das análises dos dados de continuidade dos cursos de Licenciatura em Educação do Campo realizamos algumas reflexões preliminares, que puderam ser fortalecidas com as análises dos PPCs. Os dados apresentados em relação ao número de cursos por região, como apresentado anteriormente, justificam-se pela realidade do déficit de professores com formação adequada atuando nas escolas, como constatado no Censo Escolar de 2007, ano em que se inicia o programa. Esses dados alinhados com o levantamento do I Censo Nacional da Reforma Agrária levam ao diagnóstico da necessidade de ampliação na formação de professores.

Após esse levantamento e o diagnóstico prévio sobre o universo da Educação do Campo e da sua institucionalização nos cursos de Licenciatura em Educação do Campo, essa pesquisa reforça a pertinência de uma análise em múltiplas dimensões. Sendo assim, propusemo-nos a analisar os cursos a partir das seguintes dimensões: Dimensão Pedagógica, Dimensão Política e Dimensão Geográfica.

A complexidade das relações estabelecidas nas três dimensões nos levou 
a refletir sobre os aspectos que convergem para a manutenção ou o desmantelamento da proposta de Educação do Campo. Esperávamos que as análises dos PPCs nos levassem a identificar elementos capazes de desmistificar as hipóteses inicialmente apresentadas. Para tanto, as análises foram apresentadas ao longo do texto, buscando contextualizar as dimensões e a realidade dos cursos.

\section{Dimensão Pedagógica: os objetivos que ladeiam a formação docente do curso de Licenciatura em Educação do Campo}

A formação de professores inicia-se institucionalmente no século XIX com o surgimento dos anseios por uma instrução popular após a Revolução Francesa. Com um maior número de pessoas acessando a instrução escolar, era preciso formar professores capazes de atender a essa demanda. Nesse momento, surgem as "Escolas Normais", instituições responsáveis pela formação dos professores (Saviani, 2009).

No Brasil, a formação de professores nos mesmos moldes europeus se inicia após a independência, com igual impulso da instrução popular. Em 1827 foi sancionada a Lei das Escolas de Primeiras Letras, determinando que o ensino nas Escolas Normais fosse desenvolvido através do método mútuo (Saviani, 2009). A preocupação com a formação de professores estava principalmente em conseguir atender à nova realidade.

Mesmo se aproximando de dois séculos de institucionalização da formação de professores há ainda vários fatores que vão além dos pedagógicos a serem superados. A precarização do trabalho docente pode ser apontada como um desses fatores que causam o desânimo, tornando pouco atrativa a profissão docente. Ainda que com poucos atrativos financeiros, os que se dispõem a seguir o caminho da docência também encontram problemas estruturais que os impossibilitam de permanecerem nos cursos de formação. Nas universidades públicas os subsídios financeiros que dão assistência ao tempo de formação nem sempre são suficientes.

Nesse sentido, os problemas estruturais das universidades tornam-se um empecilho para permanência nos cursos, tendo em vista que, para que efetivamente se forme professores com qualidade, os investimentos na educação devem ser contínuos. O PROCAMPO, com o financiamento do Fundo Nacional de Desenvolvimento da Educação (FNDE), minimamente buscou investir na formação de professores para atuarem no campo, tendo em vista a particularidade desse público. Os cursos de Licenciatura em Educação do Campo deveriam ofertar cursos em Regime de Alternância, dando 
condições de permanência desses sujeitos durante o curso.

A formação de professores é um instrumento caro aos movimentos de luta pela terra. Para o MST, a formação é uma oportunidade de formar um professor capaz de superar as mazelas institucionais, refletindo sobre o papel da educação em relação à formação humana e social, rompendo com a educação de mercado e utilitarista.

A Dimensão Pedagógica proposta para esta análise busca visualizar elementos relativos à formação humana e à intencionalidade nos processos formativos que os cursos de Licenciatura em Educação do Campo apresentam para conduzir os processos pedagógicos. Esses dois elementos de compreensão são apresentados para essa dimensão a partir das reflexões realizadas por Roseli Cardart no caderno Iterra:

um deles diz respeito à ideia de processo como "sentido primeiro da pedagogia"; entendendo que "a formação do ser humano se torna possível ao longo do tempo, ao longo de um processo educativo" ... A outra compreensão necessária se refere à palavra conduzir, entendida não como a ação de uma pessoa que tenta conformar o destino formativo da outra, mas sim como intencionalidade e diretividade na atuação coletiva sobre as circunstâncias objetivas em que determinado processo educativo acontece e que permite a cada pessoa fazer escolhas que vão desenhando sua ação/formação/transformação (Caldart, 2007, p. 11 ).

A Formação Humana e a intencionalidade na condução do processo formativo se fazem imprescindíveis ao se propor essa dimensão. Dentro da Dimensão Pedagógica foram pensados três elementos: (a) Objetivos do curso, (b) Auto-organização discente e (c) Proposta Interdisciplinar. Partimos do princípio de que o objetivo do curso deve ir ao encontro de uma Educação do Campo orgânica, que se complemente com o protagonismo dos educandos, dentro de uma proposta interdisciplinar que rompa com a lógica fragmentada do ensino e oportunize uma prática produtiva do homem.

Para Fazenda (2006, p. 34), “a prática produtiva do homem não se dá como trabalho individual: ela é, antropologicamente falando, expressão necessária de um sujeito coletivo". A partir do resgate das narrativas presentes nos Boletins do MST e nos Cadernos do Iterra se torna possível orientar a leitura e a escrita das impressões sobre a construção prático-teórica da Educação do Campo dentro dos cursos de Licenciatura em Educação do Campo.

Durante as análises, as indagações dialogaram com as reflexões do Caderno Iterra sobre a formação dos professores, abarcando as "intencionalidades na 
formação de educadores do campo". Os questionamentos que surgiram durante as análises nos inquietaram a pensar onde a formação de professores dentro dessas instituições se encontra com as premissas da Educação do Campo presentes nos documentos analisados.

A partir da análise dos PPCs foi apresentada uma síntese dos objetivos dos cursos de Licenciatura em Educação do Campo. A auto-organização e a proposta interdisciplinar dos cursos são apresentadas em números, considerando a quantidade de cursos que possuem ou não esses dois elementos em seus projetos pedagógicos.

\section{Síntese dos objetivos dos cursos de Licenciatura em Educação do Campo}

Dos PPCs analisados, 65\% dos cursos apresentam objetivos instrumentais, que buscam somente atender às exigências legais, 35\% trazem propostas orgânicas, com intencionalidades voltadas para a formação de educadores do campo, comprometidos com a realidade do campo. No Edital 2/2012, no item 5 (cinco), sobre a "Avaliação e Seleção dos Projetos Pedagógicos", o item 5.1.3.1, que trata da concepção teórica e metodológica dos cursos, explicita que no projeto proposto deve consistir: "formação alicerçada em saberes, teorias, metodologias, competências e práticas que integram e fundamentam os processos de ensinar e de aprender na área do objeto da formação docente, tendo como referência a realidade sociocultural do campo"

Tendo em vista o enunciado no edital 02/2012, o Quadro 4 apresenta de forma comparativa os objetivos instrumentais e orgânicos presentes nos PPCs analisados.

Quadro 4 - apresentação dos objetivos instrumentais e orgânicos identificados nos PPCs dos cursos de Licenciatura em Educação do Campo.

\begin{tabular}{|l|l|}
\hline $\begin{array}{l}\text { Objetivos Instrumentais } \\
\text { Apresentam os instrumentos legais da formação } \\
\text { de professores, sem atender às especificidades da } \\
\text { formação do Educador do Campo }\end{array}$ & $\begin{array}{l}\text { Objetivos Orgânicos } \\
\text { Apresentam em sua maioria objetivos que convergem } \\
\text { para a formação pedagógica e política no curso }\end{array}$ \\
\hline $\begin{array}{l}\text { Formar educadores para a docência nas séries finais } \\
\text { do ensino fundamental e no Ensino Médio. }\end{array}$ & $\begin{array}{l}\text { Proporcionar formação acadêmica a partir da afirmação da } \\
\text { identidade e da realidade do campo. }\end{array}$ \\
\hline $\begin{array}{l}\text { Preparar educadores para a atuação profissional } \\
\text { específica. }\end{array}$ & $\begin{array}{l}\text { Realizar uma formação contextualizada com as questões } \\
\text { do campo, possibilitando uma identidade com a formação } \\
\text { de educadores politicamente comprometidos com a } \\
\text { cultura, as lutas sociais e com o campo. }\end{array}$ \\
\hline $\begin{array}{l}\text { Suprir a demanda por educadores capacitados na área, } \\
\text { voltada para a Educação do Campo. }\end{array}$ & $\begin{array}{l}\text { Promover uma diversidade de ações pedagógicas que } \\
\text { colaborem com a garantia do direito à educação de } \\
\text { qualidade no campo e como ferramenta de } \\
\text { desenvolvimento social. }\end{array}$ \\
\hline
\end{tabular}




\begin{tabular}{|c|c|}
\hline $\begin{array}{l}\text { Propiciar a demanda interdisciplinar sólida e } \\
\text { abrangente de profissionais da educação. }\end{array}$ & $\begin{array}{l}\text { Proporcionar uma formação que possibilite aos sujeitos } \\
\text { formação político-pedagógica para atuarem no campo. }\end{array}$ \\
\hline Cumprir a Política Nacional de Educação do Campo. & $\begin{array}{l}\text { Contribuir para a construção de uma Educação do Campo } \\
\text { vinculada às causas, aos desafios, à história e à cultura do } \\
\text { trabalhador do campo. } \\
\text { Garantir a constituição de um espaço de formação } \\
\text { orientado pelas concepções. }\end{array}$ \\
\hline $\begin{array}{l}\text { Formar o licenciado dentro das áreas de } \\
\text { conhecimento. }\end{array}$ & $\begin{array}{l}\text { Formar educadores e educadoras do campo } \\
\text { comprometidos com os princípios da Educação do Campo } \\
\text { e o desenvolvimento social sustentável. } \\
\text { Legitimar o empoderamento das comunidades locais, } \\
\text { fundamentado na democratização da ciência e da } \\
\text { tecnologia. } \\
\text { Formar professores que valorizem o espaço rural como } \\
\text { produtor de vida, cultura, riqueza e conhecimento. }\end{array}$ \\
\hline
\end{tabular}

Fonte: Paula (2020).

\section{Auto-organização dos discentes}

No item Auto-organização dos discentes, somente 2 (dois) cursos apresentam elementos concretos sobre a auto-organização dos alunos e somente 1 (um) curso fala de Formação Humana.

Na UFBA está descrita, dentro dos princípios pedagógicos do curso, a autoorganização dos estudantes. $\mathrm{Na}$ UFRB/Campus de Amargosa o projeto deixa claro que "Este curso valoriza também, a auto-organização dos estudantes no intuito de possibilitar espaços para a autonomia $e \quad o$ protagonismo destes no processo educacional".

Os demais cursos apresentam somente as instâncias administrativas em que o aluno pode ser assistido, voltadas principalmente para direitos e deveres institucionais. Vale ressaltar que a participação dos estudantes na construção do curso dialoga com a perspectiva da "Escola do Trabalho", já apresentada ao longo deste trabalho, alinhada às perspectivas do Setor de Educação do MST.

Para o MST, o educando deve saber lutar e saber construir, ao passo que o trabalho educa e é capaz de mexer com as dimensões da formação humana, tão importante na Educação do Campo. Em um curso que se faz dentro da premissa da luta e da resistência diária, o protagonismo presente na auto-organização dos estudantes não pode ser sublimado.

Para Caldart (2012), o educador da terra se orienta por uma visão alargada de Educação, sendo capaz de se vincular aos processos de formação do ser humano e alargar consequentemente sua tarefa, seu horizonte de trabalho.

A compreensão das intencionalidades de educação/formação de 
pessoas deve estar presente desde a formação inicial do professor, rompendo com os reducionismos, que, segundo Caldart (2012), são produto da visão moderna/liberal, que acredita que "educação é igual a escola e de que a escola é igual a ensino, sendo a dimensão da 'instrução' a única para a qual efetivamente se precisa preparar o educador, e de preferência de uma forma apenas instrumental" (Caldart, 2012, p. 123, grifos do autor).

Nesse viés, esperamos que os cursos de formação de educadores para o campo se comprometam a refletir sobre o papel da escola, que vai além do de instrução, voltado somente para as questões cognitivas. É preciso que os estudantes possam compreender, ainda na formação inicial na universidade, que as construções coletivas devem ser cotidianas e devem fazer parte da transformação do ser humano.

Dentro das perspectivas da educação do movimento, "é possível organizar processos educativos que vão construindo o protagonismo dos educandos na condução de sua própria formação. E isso se consegue mais facilmente quando se desindividualiza o processo." (Caldart, 2012, p. 129). São os sujeitos coletivos fazendo a autocondução do processo formativo, democratizando as estratégias pedagógicas que se propõem para formar educadores para o campo.

\section{Proposta interdisciplinar}

Com este mesmo olhar voltado para a intencionalidade da formação dos educadores do campo foi elaborada a análise da "Proposta Interdisciplinar" dos cursos. O objetivo foi identificar se os cursos apresentam uma proposta interdisciplinar em seus projetos. No Boletim 20 anos do MST (2004), a interdisciplinaridade aparece como uma forma de fazer o saber ter sentido para os educandos, ressaltando a importância da articulação entre os professores, que vinculam entre si várias áreas do saber.

No Edital 02/2012 os projetos deveriam apresentar estratégias de formação para a docência multidisciplinar, por áreas do conhecimento, o que demanda possibilidades de intervenções interdisciplinares na formação desses sujeitos.

As questões da vida real devem dialogar permanentemente com a teoria e a prática, criando uma postura investigativa, de interpretação da realidade. Os professores formadores em constante diálogo são fundamentais nessa construção.

Por meio das análises foi possível identificar que, em sua maioria, os cursos 
trazem uma proposta interdisciplinar em seus projetos. Somente duas instituições não apresentaram a interdisciplinaridade em sua proposta pedagógica. Alguns cursos tratam a interdisciplinaridade em uma lógica "disciplinar", considerando a possibilidade de uma construção interdisciplinar somente em disciplinas de prática pedagógica ou eixos temáticos. Para Fazenda (1998, p.13), “o primeiro passo para a aquisição conceitual interdisciplinar seria o abandono das posições acadêmicas prepotentes, unidirecionais e não rigorosas que fatalmente são restritivas, primitivas e "tacanhas", impeditivas de aberturas novas."

Após a análise dos PPCs, foram selecionados alguns trechos que discorrem sobre a interdisciplinaridade nos cursos. Destacamos os seguintes trechos recorrentes nos PPCs, que expressam possibilidades interdisciplinares:

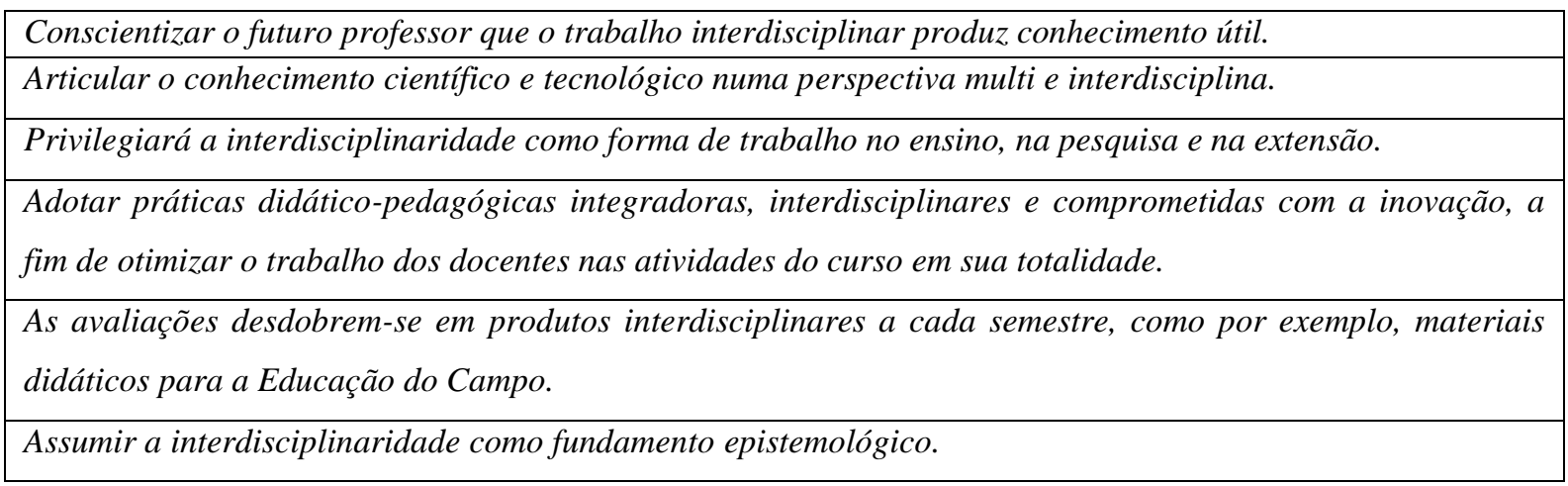
Fonte: Paula (2020).

Os trechos apresentados reforçam uma prática utilitarista e instrumentalizada na realização da interdisciplinaridade. Ela aparece como uma forma funcional, com elementos que a tornariam capaz de oferecer produtos e direcionar condutas. Por vezes, está voltada somente para a atividade prática, ou somente para o desdobramento teórico, desconsiderando que um olhar "interdisciplinarmente atento recupera a magia das práticas, a essência de seus movimentos, mas, sobretudo, induz-nos a outras superações, ou mesmo reformulações" (Fazenda, 2006, p. 13).

Podemos perceber como os três elementos analisados se entrelaçam na compreensão da construção dos PPCs dos cursos de Licenciatura em Educação do Campo. Diante disso, compreender os objetivos, o protagonismo discente e a proposta interdisciplinar dos cursos nos leva a perceber os fios que se unem a um 
projeto formativo para a Educação do Campo.

Em Caldart (2012, p. 140), é possível convergirmos essas reflexões quando ela afirma que "um curso em si mesmo não tem a força material necessária ao enraizamento de uma prática social como a Educação do Campo, mas o projeto formativo que o produz e se produz a partir dele, pode compor o processo de "territorialização desta prática."

Para darmos continuidade às análises, a segunda dimensão apresentada é a Dimensão Política, compreendendo que as dimensões se complementam na reflexão sobre o processo de institucionalização e as convergências com os princípios que norteiam a Educação do Campo, que se fazem pedagógicos, políticos e territoriais.

\section{Dimensão política: a formação política e o protagonismo dos movimentos sociais na construção dos cursos de Licenciatura em Educação do Campo}

A Dimensão Política está entrelaçada a todas as outras dimensões da Educação do Campo. Ao falarmos na luta da classe trabalhadora por escola pública, da escola do trabalho e da formação humana ética, que leve o sujeito a ser capaz de lutar pelas transformações sociais, inevitavelmente falamos da formação política desses sujeitos.
Reconhecemos, portanto, que essa dimensão vai nortear as outras duas propostas, pois a "escola que cabe na pedagogia do movimento é, pois uma escola, que não cabe nela mesma". É a formação política dos professores que será capaz de levá-los a compreender que a escola vai além de sua estrutura física ou pedagógica, ela transcende o universo escolar e chega às propriedades, aos currículos escolares e às disputas territoriais. Nesse sentido, ela vivencia o que os movimentos afirmariam como uma forma de romper com as cercas que a aprisionam.

Caldart (2012) considera que o processo de formação de professores deve sempre retomar sua materialidade de origem, constituindo-se como um projeto educacional "vinculado às lutas sociais camponesas, de natureza anticapitalista e voltado à construção de um novo projeto de nação, de sociedade, de campo" (Caldart, 2012, p. 141).

Ao analisarmos a Dimensão Política dos projetos dos cursos, situamos a importância da formação política dos futuros professores. Nesse sentido, apresentamos dois itens analisados: o perfil dos discentes que ingressam nos cursos e as articulações do curso com os movimentos sociais. 
No Edital 02/2012, considerando que esse movimento é um fortalecedor do diálogo entre a formação de educadores do campo, esses dois elementos aparecem como essenciais na construção do projeto. $\mathrm{O}$ atendimento ao perfil discente foi um critério fundamental para a participação do edital. No item 3.5, letra b, está descrito que o curso deve "prever os critérios e instrumentos para uma seleção específica a fim de contribuir para o atendimento da demanda por formação superior dos professores das escolas do campo, com prioridade, para aqueles em efetivo exercício". No que tange à articulação com os movimentos sociais, este aparece como elemento a ser avaliado nas propostas no item 5.1.3.1, letra g, ao afirmar que o projeto deve prever "articulação com um conjunto de movimentos sociais e sindicais do campo ou Comitês Estaduais de Educação do Campo".

Uma preocupação dos movimentos de luta pela terra que iniciaram a proposição de uma Educação do Campo e que está presente no Boletim 20 anos do MST (2004) é manter a identidade própria das escolas do campo, com um projeto pedagógico que fortaleça o campo. Esse desafio só se torna possível ao passo que os professores que atuam nessas escolas sejam formados se pautando no compromisso com os sujeitos do campo, em vista de justiça social, do respeito à vida e da valorização da cultura camponesa.

A previsão de instrumentos seletivos específicos está presente desde o primeiro edital em 2008. Esse encaminhamento faz parte das pautas da luta dos movimentos sociais, que pretendem fazer dos quadros de exclusividade pedagógica existentes nas universidades um lugar de validade dos saberes construídos no campo.

Arroyo (2014) propõe a reflexão sobre como a teoria pedagógica resiste em não reconhecer os saberes dos "Outros", apegando-se à supremacia do saber de "levar os ignorantes para o conhecimento" e é pela resistência desses grupos sociais que "esses seres pensados inferiores portadores de saberes inferiores se afirmam sujeitos de Outras Pedagogias e de outros saberes e fazem desse território tão cercado um campo de disputa política" (Arroyo, 2014, p. 32). Estabelecer o território camponês na universidade só ganha materialidade na medida em que afirmativamente esse espaço é dado a eles. Arroyo (2014, p. 81) afirma que:

os movimentos sociais em sua diversidade de fronteiras coincidem em destacar como o aprendizado dos direitos vem das lutas por essa base material. Por sua humanização. Os movimentos sociais têm sido educativos não tanto por meio da propagação de discursos e lições conscientizadoras, mas pelas formas 
com que têm se agregado e mobilizado em torno das lutas pela sobrevivência, pela terra, pelo trabalho ou pela inserção na cidade.

Os movimentos sociais de luta pela terra foram capazes de trazer para a universidade um fazer pedagógico, legitimado através dos editais de seleção dos cursos, que desse centralidade às lutas sociais que se encontram em pauta. Conforme o curso se constrói nas bases dos movimentos sociais, espera-se que a intencionalidade da educação e da formação desses sujeitos seja capaz de alargar a concepção de formação humana, rompendo com os reducionismos instrucionais que predominam na educação.

O educador do campo, a partir de sua experiência social, deverá ser capaz de aliar teoria e prática em um "movimento que é de autotransformação humana, de modo a poder ajudar a desencadeá-la nos processos educativos que acompanha." (Caldart, 2012, p. 126).

Nesse sentido, ao analisarmos o perfil esperado do aluno que ingressa nos cursos de Licenciatura em Educação do Campo e a relação estabelecida entre os cursos e os movimentos sociais, mesmo que minimamente, compreendemos os princípios que norteiam o curso, quer sejam institucionais ou orgânicos, com centralidade nas lutas sociais e na valorização do campo.

O protagonismo dos sujeitos que vivem no campo, seja como educadores em formação, seja como articuladores desse movimento dá centralidade ao "intenso processo de disputa pela transformação da realidade social camponesa e busca da melhoria de vida no campo, pela superação de suas necessidades materiais e imateriais" (Ferreira \& Molina, 2014, p. 127).

\section{Perfil dos discentes/critérios de ingresso}

$\mathrm{Na}$ análise do item "Perfil dos discentes/critérios de ingresso", percebemos que $57 \%$ dos PPCs analisados apresentavam critérios de prioridade para o ingresso a: a) estudantes vinculados ao campo; b) professores que não tenham formação em nível superior; c) trabalhadores do campo; e d) façam parte de movimentos sociais.

Em algumas universidades estava previsto que as vagas eram "exclusivamente" para atender aos povos do campo. Outras universidades, após atenderem ao critério de prioridade, disponibilizam as vagas para alunos que tenham concluído o ensino médio, sem necessariamente estarem vinculados às atividades camponesas. Essa prerrogativa pôde ser confirmada no levantamento dos 
editais abertos para a seleção 2019/2020. Os cursos, em sua maioria, reforçam os critérios de prioridade, sendo possível identificar cursos que reforçam a "exclusividade" de acesso a candidatos com vínculo com o campo.

\section{Articulação com os movimentos sociais}

$\mathrm{Na}$ análise do item “Articulação com movimentos sociais", vemos uma diversidade de representações sobre essa possível articulação. Efetivamente, somente 56\% dos cursos apontam uma articulação com os movimentos na construção dos cursos. Os demais PPCs suprimem essa informação e não apresentam a articulação com os movimentos sociais.

Nos cursos que apontam a articulação com os movimentos, essa participação foi identificada como uma intervenção esporádica, fruto de parcerias para o desenvolvimento de projetos de pesquisa, extensão e/ou através da participação no PRONERA.

Dos 48 PPCs analisados, somente uma instituição tem um membro dos movimentos sociais na Comissão Permanente de Avaliação do Curso. Em sua maioria, a participação dos movimentos sociais é marginal, eles aparecem como colaboradores nas atividades do Tempo Comunidade, em eventos e projetos de extensão, portanto, sem contribuir efetivamente com o curso.

$\mathrm{Na}$ II Conferência Nacional de Educação do Campo (CNEC), que ocorreu em agosto de 2004 em Luziânia, aproximadamente 1100 representantes de movimentos sociais, sindicatos, professores e Organizações Não Governamentais (ONGs) assinaram a declaração final do evento, que foi posteriormente publicada em periódicos e outros meios de comunicação. $\mathrm{O}$ documento traz elementos pertinentes à luta por direitos sociais para o campo.

Sobre uma política pública permanente para a formação de profissionais para o campo, os movimentos sociais solicitavam que houvesse "formação e qualificação vinculadas à Educação do Campo, junto às universidades construídas coletivamente com os sujeitos do campo, às equipes técnicas contratadas e aos órgãos públicos responsáveis pela assistência técnica" e "cursos de nível médio e superior que incluam os jovens e adultos trabalhadores do campo e que priorizem a formação apropriada para os diferentes sujeitos do campo" (Cnec, 2004, p. 7).

Na análise da Dimensão Política podemos afirmar que o compromisso com os anseios por uma Política Pública de Educação do Campo, apoiada pelos 
movimentos sociais e outras instituições, ainda é incipiente dentro dos cursos de Licenciatura em Educação do Campo, considerando que não há uma política de prioridade de acesso constante nos mesmos e a articulação com os movimentos sociais não corresponde a uma efetiva participação na construção e avaliação do curso.

\section{Dimensão Geográfica: representação do território da Educação do Campo}

A análise da dimensão geográfica das Licenciaturas em Educação do Campo apresenta elementos que norteiam a representação geográfica dessas instituições e o que consequentemente levou ao interesse em ofertar um curso com a especificidade da Educação do Campo, objeto de lutas sociais que transcendem a luta por educação. Dois itens foram propostos: (a) disputas territoriais e (b) presença de movimentos sociais de luta pela terra ou outros segmentos no território da instituição.

Levamos em consideração a multiplicidade de territórios presente e envolta em uma instituição, considerando inclusive territórios que se constituem dentro da própria instituição.

A análise geográfica dentro da perspectiva da Educação do Campo não pode estar descolada dos paradigmas que surgem da complexidade do campo brasileiro e do constante desenraizamento desses sujeitos de suas terras, de suas histórias e sua cultura. Para Arroyo (2014, p. 203),

Desenraizar os povos originários e a diversidade de grupos populares foi e continua sendo os processos mais desumanizadores em nossa história. $\mathrm{Na}$ medida em que decretam seus territórios ilegais, inexistentes, decreta-se a inexistência das bases de sua produção como humanos, culturais, sujeitos de memórias, valores, identidades coletivas.

No Edital 02/2012, no item 5.1.3.1, letra b, está estabelecido que fosse apresentado um "diagnóstico sobre a demanda quantitativa e qualitativa de formação de professores do campo no contexto dos anos finais do ensino fundamental e do ensino médio no âmbito das comunidades a serem atendidas pelo projeto.” Esse item leva em consideração a multiplicidade do campo e a diversidade da demanda para se alcançar o perfil esperado para ingresso no curso.

\section{Disputas territoriais}

Ao iniciar as análises, foi possível identificar a ausência da apresentação dos territórios de forma explícita. Durante as consultas aos PPCs, como forma de identificar a representação desses territórios, pesquisamos as palavras-chave: território; disputa e luta. Para essas 
palavras, a correspondência era "nenhuma ocorrência" ou, quando apareciam, faziam parte das ementas de disciplinas ou das bibliografias.

Mesmo de forma implícita identificamos os territórios e a presença de movimentos sociais dentro da apresentação dos cursos. Os territórios indígenas, quilombolas, do agronegócio, da indústria, de pequenos proprietários de terra, de assentamentos e outros se fizeram presentes na apresentação das instituições.

Identificamos múltiplos territórios voltados a diferentes perspectivas do campo, como é o caso da Universidade Federal de Viçosa, que em sua descrição institucional reforça a excelência em "pesquisas e produtos orientados para o desenvolvimento do agronegócio" e, ao mesmo tempo, abriga um "observatório dos movimentos sociais". Uma disputa territorial presente dentro de uma mesma instituição.

Outro elemento que pôde ser visualizado em alguns PPCs foi o campo como espaço de produção de mercadorias, sendo que, por vezes, há somente relatos das atividades produtivas do município ou da presença de pequenas propriedades ou propriedades voltadas para a agricultura familiar. As relações estabelecidas no território da Educação do Campo, portanto, transcendem a luta pela terra ao passo que se busca legitimar esse território dentro da complexidade que o cerca.

Fernandes (2006, p.30) considera que “...os territórios são espaços geográficos e políticos, onde os sujeitos sociais executam seus projetos de vida para o desenvolvimento. Os sujeitos sociais organizam-se por meios das relações de classe para desenvolver seus territórios." E é nesse movimento que a Educação do Campo se estabelece e vai constituindo sua territorialidade.

A relação estabelecida entre os cursos de Licenciatura em Educação do Campo, os territórios que os cercam e os movimentos sociais que os fortalecem vai possibilitar a territorialização da Educação do Campo. Fernandes (2006, p.37) define "territorialização como resultado da expansão do território, contínuo ou interrupto, a territorialidade é a manifestação dos movimentos das relações sociais mantenedoras dos territórios que produzem e reproduzem ações próprias ou apropriadas".

É possível verificar nas apresentações institucionais que, ao mesmo tempo em que a Educação do Campo está presente, ela é desterritorializada pelos interesses do agronegócio, da indústria, da mineração e de tantas outras frentes capitalistas que, por vezes, financiam as 
pesquisas nas universidades por meio de pactos de cooperação.

\section{Presença de movimentos sociais de luta pela terra ou outros segmentos no território da instituição}

Ao analisarmos a presença dos movimentos sociais de luta pela terra e demais movimentos nos territórios dos cursos, observamos PPCs sem um diagnóstico da realidade do território, reforçando o que já havia sido identificado na articulação com os movimentos sociais na Dimensão Política. Há na construção dos cursos uma ausência de participação desses movimentos e aparentemente até mesmo uma invisibilidade, haja vista que, por vezes, é omitida a presença desses sujeitos.

Os PPCs que apontaram a presença desses movimentos sociais citam uma diversidade dos mesmos: associações de agricultores, de pescadores e da agricultura familiar; Via Campesina; MST; Movimento de Liberdade dos Sem Terra e assentamentos da reforma agrária sem a identificação do movimento de que fazem parte; Escolas Família Agrícola; Federação de trabalhadores rurais; Sindicatos rurais e dos povos da floresta.

A região Sul, seguida da região Centro-Oeste, foram as que mais descreveram em seus projetos a presença de diversos movimentos que compõem o território onde estão localizadas. Essa presença orgânica dos movimentos no território das universidades vai ao encontro dos anseios apresentados nas articulações que balizaram uma política para a Educação do Campo.

Na Declaração final do Congresso Nacional Educação do Campo, em 2004, foi reafirmada a luta social "por um campo visto como espaço de vida e por políticas públicas específicas para sua população" e, para que essa realidade se efetive, a linha tênue que une a universidade $\mathrm{e}$ os movimentos sociais não pode ser rompida. A Declaração afirma que os movimentos sociais defendem "uma educação que ajude a fortalecer um projeto popular de agricultura que valorize e transforme a agricultura familiar/camponesa e que se integre na construção social de um projeto de desenvolvimento sustentável de campo e de país.” (Cnec, 2004).

O movimento de Educação do Campo notadamente viu os cursos de Licenciatura em Educação do Campo como uma ponte entre o campo e a universidade, sem considerar a possibilidade de que efetivamente a universidade não estivesse pronta para esse diálogo, tendo em vista suas amarras institucionais.

Diante dessa análise diagnóstica que, apesar de não ter alcançado a totalidade 
dos cursos, analisou $68,5 \%$ dos cursos que já se propuseram a ofertar a Licenciatura em Educação do Campo e 84\% dos cursos que se encontram ativos, concluímos que, frente ao que se esperava das propostas a partir dos editais e dos documentos do MST e do Iterra no que tange à formação de educadores do campo, há um afastamento das propostas pedagógicas desses cursos das expectativas dos movimentos sociais de luta pela terra. Temos, portanto, clareza de que os documentos nem sempre correspondem à realidade vivenciada cotidianamente no universo dos cursos, o que nem mesmo uma pesquisa in loco possivelmente nos responderia.

A Educação do Campo vista a partir de sua institucionalização deve ser entendida como a materialização de uma política de formação de professores para o campo, mas arrisca se esvaziar se abrir mão de preceitos que constituem a proposta, o que, por vezes, desterritorializa a mesma no território acadêmico.

As análises dentro das três dimensões apresentadas nos inquietaram a refletir sobre os caminhos de reterritorialização da Educação do Campo. Diante dessa realidade, ainda é possível identificar elementos fortalecedores da temática no âmbito acadêmico, realizando uma reflexão sobre as experiências vivenciadas até o momento como propulsoras de possibilidades de reterritorialização à luz da dinâmica territorial do MST.

Ao fim deste trabalho podemos afirmar que encontramos "Educações dos Campos", e, mesmo que o termo não seja harmonioso foneticamente, na realidade das IES é o que vem se constituindo. A hipótese apresentada inicialmente se confirma quando vemos que os cursos se afastaram da essência da Educação do Campo gestada pelo MST, mas é refutada quando se pode afirmar que a Educação do Campo jamais se construiria fora de sua matriz formadora, mesmo que em contextos diferentes.

\section{Referências}

Arroyo, M. G. (2014) Outros sujeitos, outras pedagogias. 2. ed. Petrópolis, RJ: Vozes.

Caldart, R. (2004). Por uma Educação do Campo: traços de uma identidade em construção. In Arroyo, Miguel G., Caldart, R. S., \& Molina, M. C. (Orgs). Por uma Educação do Campo (s./p.). Petrópolis, RJ: Vozes.

Caldart, R. S. (2007). Sobre Educação do Campo. In Santos, C. A. (Org.). Por Uma Educação do campo (s./p.). Brasília: Incra: MDA.

Caldart, R. (2012). Intencionalidades na formação de Educadores do Campo: reflexões desde a experiência do curso "Pedagogia da Terra da Via Campesina". 
In Antunes-Rocha, M. I., Almeida Martins, M. F., \& Alves Martins, A. (Orgs.). Territórios educativos na Educação do Campo: escola, comunidade e movimentos sociais (s./p.). Belo Horizonte, MG: Autêntica.

Caldart, R., Pereira, I. S., Alentejano, P., \& Frigoto, G. (Orgs.). (2012). Dicionário da Educação do Campo (s./p.). São Paulo: Escola Politécnica de Saúde Joaquim Venâncio, Expressão Popular.

Conferência Nacional de Educação do Campo. (2004). Por uma Política Pública de Educação do Campo. 2. Luziânia-GO. Texto Base. Luziânia-GO.

Edital N. 02, de 23 de abril de 2008 (2008, 23 de abril). Chamada pública para seleção de projetos de instituições públicas de ensino superior para o PROCAMPO.

Edital N. 09, de 29 de abril de 2009 (2009, 29 de abril). Edital de convocação.

Edital N. X/2012. (2012). Edital de seleção SESU/SETEC/SECADI/MEC.

Fazenda, I. (Org.). (1998). Didática e interdiscinaridade. $12^{\mathrm{a}}$ ed. Campinas, Papirus.

Fazenda, I. (2006). O sentido da ambiguidade numa didática interdisciplinar. In Pimenta, S. G. (Orgs.). Didática e formação de professores: percursos e perspectivas no Brasil e em Portugal (s./p.). São Paulo: Cortez.

Fernandes, B. M. (2006). Os campos da Pesquisa em Educação do Campo: espaço e território como categorias essenciais. In Molina, M. C. (Org.). Educação do Campo e Pesquisa: questões para reflexão (s./p.). Brasília: Ministério do Desenvolvimento Agrário.

Ferreira, M. J. L., \& Molina, M. C. (2014). Desafios à formação de Educadores do
Campo: tecendo algumas relações entre os pensamentos de Pistrak e Paulo Freire. In Molina, M. C. (Org.). Licenciaturas em Educação do Campo e o ensino de Ciências Naturais: desafios à promoção do trabalho docente interdisciplinar (s./p.). Brasília: MDA (Série NEAD Debate; 23).

IBGE - Instituto Brasileiro de Geografia e Estatística. (1996). Censo agropecuário 1996. Rio de Janeiro: IBGE, 1996. Recuperado em: www.ibge.gov.br

Lei $\mathrm{n}^{\circ} 9.42424$ de dezembro de 1996 (1996, 24 de dezembro). Dispõe sobre o Fundo de Manutenção e Desenvolvimento do Ensino Fundamental e de Valorização do Magistério, na forma prevista no artigo $30, \S 7^{\circ}$, do Ato

das Disposições Constitucionais Transitóri as e dá outras providências.

MST. Movimento dos Trabalhadores Rurais Sem Terra. (1992). Boletim da Educação n. 1. Ocupar, produzir e resistir. 1. ed. Setor de Educação do MST.

MST. Movimento dos Trabalhadores Rurais Sem Terra. (1993). Boletim da Educação n. 2. Como trabalhar a mística do MST com as crianças. 1. ed. Setor de Educação do MST.

MST. Movimento dos Trabalhadores Rurais Sem Terra. (1993). Boletim da Educação n. 3. Como trabalhar a comunicação nos assentamentos e acampamentos do MST. 1. ed. Setor de Educação do MST.

MST. Movimento dos Trabalhadores Rurais Sem Terra. (1994). Boletim da Educação n. 4. Escola, trabalho e cooperação. 1. ed. Setor de Educação do MST.

MST. Movimento dos Trabalhadores Rurais Sem Terra. (2004). Boletim da Educação n. 9. Educação no MST, balanço 20 anos. 1. ed. Setor de Educação do MST. 
Paula, H. V. C. (2020). Territórios e projetos em disputa na institucionalização dos cursos de licenciatura em educação do campo (Tese de Doutorado). Universidade Federal de Uberlândia, Uberlândia.

Saviani, D. (2009). Formação de professores: aspectos históricos e teóricos do problema no contexto brasileiro. Rev. Bras. Educação 14(40), 143-155. https://doi.org/10.1590/S1413$\underline{24782009000100012}$

Informações do Artigo / Article Information

Recebido em : 04/06/2021

Aprovado em: 13/03/2021

Publicado em: 30/11/2021

Received on June 04th, 2021

Accepted on March 13th, 2021

Published on November, 30th, 2021

Contribuições no Artigo: Os(as) autores(as) foram os(as) responsáveis por todas as etapas e resultados da pesquisa, a saber: elaboração, análise e interpretação dos dados; escrita e revisão do conteúdo do manuscrito e; aprovação da versão final publicada.

Author Contributions: The author were responsible for the designing, delineating, analyzing and interpreting the data, production of the manuscript, critical revision of the content and approval of the final version published.

Conflitos de Interesse: Os(as) autores(as) declararam não haver nenhum conflito de interesse referente a este artigo.

Conflict of Interest: None reported.

\section{Avaliação do artigo}

Artigo avaliado por pares.

\section{Article Peer Review}

Double review.

\section{Agência de Fomento}

Não tem.

Funding

No funding.

\section{Como citar este artigo / How to cite this article}

APA

Paula, H. V. C., \& Chelotti, M. C. (2021). As memórias como ponto de partida: os projetos pedagógicos como diagnóstico da realidade institucional dos cursos de Licenciatura em Educação do Campo. Rev. Bras. Educ. Camp., 6, e9557. http://dx.doi.org/10.20873/uft.rbec.e9557

ABNT

PAULA, H. V. C.; CHELOTTI, M. C. As memórias como ponto de partida: os projetos pedagógicos como diagnóstico da realidade institucional dos cursos de Licenciatura em Educação do Campo. Rev. Bras. Educ. Camp., Tocantinópolis, v. 6, e9557, 2021. http://dx.doi.org/10.20873/uft.rbec.e9557 